Becoming Scholars in an Interdisciplinary, Feminist Learning Context

Victoria Pileggi

Joanna Holliday

Carm de Santis

Andrea LaMarre

Nicole Jeffrey

Maria Tetro

Carla Rice 


\section{Becoming Scholars in an Interdisciplinary, Feminist Learning Context}

Victoria Pileggi, Joanna Holliday, Carm de Santis, Andrea LaMarre, Nicole Jeffrey, Maria Tetro, and Carla Rice

Introduction

Feminist classrooms and transformative learning: contextualizing ourselves

Feminist classrooms have become scholarly spaces where instructors, committed to the principles and processes of feminism, are able to seek out and employ creative ways to engage with teaching and learning processes (Gardiner 411). These classrooms are designed to be responsive to students' needs, experiences, and ways of being (Bryson and Bennet-Anylkwa 133; Hobbs and Rice, "Rethinking" 139), while also inviting instructors to "experiment with new, sometimes risky, pedagogical approaches" (Mahar and Thompson Tetreault 2). Feminist pedagogues value, recognize, and encourage each student's voice, and they view students as active participants in the learning process (hooks, qtd. in Donadey 83).

Transformative processes are implicated in undertaking, establishing, and instituting change on individual, collective, and structural levels in feminist classrooms (Hobbs and Rice, "Introduction" xviii). On a structural level, Carolyn Shrewsbury writes: "[f]eminist pedagogy ultimately seeks a transformation of the academy and points toward steps, however small, that we can all take in each of our classrooms to facilitate that transformation ... [By centralizing] three concepts, community, empowerment, and leadership ... [as] a way of organizing our exploration into the meaning of feminist pedagogy" (9-10). Shrewsbury encourages feminist pedagogues to resist the structural constraints inherent in traditional learning environments and to create spaces that generate transformative learning for students and instructors. In so doing, feminist 
pedagogies can shift orthodox arrangements and practices in the academy. By creating a learning environment that is attuned to power dynamics and structures, feminist pedagogy can generate provisional communities. Shrewsbury conceptualizes such communities as those wherein "both autonomy of self and mutuality" (12) of members' learning and developmental needs can be met by consensual "participatory and democratic" (13) processes, regardless of participants' identities and differences, social positionalities, and shifting power dynamics.

Jerilyn Fisher contends that a feminist classroom emphasizes experiential and collaborative learning, promotes self-directed learning, and honors adult life transitions (125). Each learner is invited to be reflective and to create, validate, and build connections with their own and others' lived experiences (122). This reflective process allows learners to undertake self-directed learning while contributing to and expanding on the collective quality of learning as they make connections between theory and practice (124). During this process, students' perceptions of themselves as learners and as women (though these classrooms generally welcome students of all genders and often engage with queer and transfeminist theory) may also change. Fisher notes that feminist teaching can help learners to "more smoothly navigate the tides" of their personal development (126).

Feminist classrooms focus on "consensual, collaborative, non-hierarchical processes of learning and teaching" (Kenway and Modra 149), and both students and instructors are subject to the dynamic processes of power-sharing and knowledge construction (Bryson and Bennet-Anylkwa 134). The role of authority is generally deemphasized (Donadey 83), as instructors engage in various processes that affirm students' expertise, promote their critical thinking skills, and support their movement into the role of teacher (Bryson and Bennet-Anylkwa 134).

Some feminist pedagogues believe that traditional lecture-style university classrooms, where students are considered "passive receivers of knowledge" (Bryson and Bennet-Anylkwa 133), are ineffective modes of instruction. Within a critical feminist pedagogical framework, instructors aim to engage more effectively with students; 
instead of positioning themselves as privileged knowledge producers and knowledge disseminators, they become moderators, facilitators, questioners, and conflict negotiators (Nixon et al. 203; Spencer 199) who attempt to democratize knowledge creation and sharing. Transformative learning environments aim to promote clear collaboration between students and instructors (Locke and Kiselica, qtd. in Nixon et al. 203). This can include soliciting student input on course syllabus creation, arranging the physical structure of the classroom to enable discussion, and using a variety of readings that represent the vast assortment of student values, interests, and positionalities (Spencer 203).

Related to the intentional diffusion of power in feminist classrooms, many feministinformed instructors aspire to cultivate "safe spaces" that support various views, build trust among participants, and empower student expression (Bryson and Bennet-Anylkwa 135; do Mar Pereira 129; Gardiner 411; Seymour 197). In his work with feminist instructors, Leland Spencer identifies approaches for constructing and implementing learner safety in scholarly spaces, including developing "ground rules" for courteous dialogue, deemphasizing the need to "win" arguments, engendering "mutual respect for differences," and ensuring that certain perspectives, including those of the instructor, do not take precedence over others $(203,208)$. Through participating in a mutually respectful and safe learning space, students are more likely to feel empowered to use their voices and pose questions freely and to learn that their perspectives matter (Bryson and Lawrence-Webb, qtd. in Bryson and Bennet-Anylkwa 135). This sense of "mattering" can encourage students to take intellectual risks, to think in novel ways, and to establish a personal commitment to the learning process both inside and outside of the classroom (Bryson and Bennet-Anylkwa 135; Kishimoto and Mwangi 96; Shrewsbury 13).

Some authors, however, critique this rhetoric of safety (Kishimoto and Mwangi 88). For instance, bell hooks suggests that feminist classrooms might be used to help instructors and students "learn to appreciate difficulty, too ... or accept that that cozy, good feeling may at times block the possibility of giving students space to feel that there is integrity to be found in grappling with difficult material" (qtd. in Kishimoto and Mwangi 89). Maria do Mar Pereira refers to these moments as those of "didactic discomfort" (129), 
referencing how course materials and/or methods might be intellectually and emotionally unsettling but also challenging and generative for students.

Emotion may be particularly important in feminist classrooms. Unlike traditional academic spaces that aim to divorce "reason from feelings" (Martin 81), feminist pedagogical practices attempt to invite, accept, and facilitate the bridging of reason and feeling. For many feminist educators, the heart and head do not exist as two distinct metaphoric pathways to knowing; rather, they are intertwined (B. Fisher 84). In some feminist classrooms, emotionality is recognized not only as emanating from participants (B. Fisher 76), but also as generated in participants' engagement with difficult knowledge and newperspectives (De Santis and Serafini 99). Processing emotionality in the classroom requires collective patience, collaborative inquiry, and improvisation (B. Fisher 1993). Emotionality can also foster engaging discussion, valuing of experiential knowledge, exploration of feminist beliefs and values, and trust and intimacy among instructors and students (B. Fisher 78).

The above principles work together to "trigger intense pedagogical events" that B. J. Bryson and Victoria Bennet-Anylkwa term "teachable moments" (135). In these fleeting instances, sometimes safe, oftentimes uncomfortable, and frequently generative, emotionally charged sharing may initiate deeply personal experiences of meaning-making. "Teachable moments" are highly contextualized and unpredictable; they cannot be repeated through formulaic or pre-scripted techniques, but rather arise from the unique social, political, and affective relationships cultivated among learners, instructors, and content (135). Feminist pedagogues anticipate these moments regardless of their brevity and capriciousness, however, and often believe that they make learning "real" for students.

\section{Legacies of feminist pedagogies: delivery and outcome in}

\section{interdisciplinary feminist classrooms}

As feminist pedagogy has gained traction over the last twenty years, a number of North American feminist instructors have committed to transforming their classrooms to 
incorporate its principles. For instance, in her revised offering of Shrewsbury's Feminist Pedagogies undergraduate course at Minnesota State University, Mankato (known at the time as Mankato State), Clare Bright attempted to integrate theory and personal growth by involving students in course creation and implementation (129). Though initially resistant to the diffusion of power, students worked collaboratively to construct the course syllabus, decide on course objectives, and generate guidelines for course assessment and evaluation (129). In addition to these administrative tasks, students were also charged with facilitating weekly discussions and evaluating themselves and each other throughout the course (130). Although Bright does not highlight specific student outcomes, she suggests that these classroom conditions contribute to "pedagogical competence," the translation of feminist theory into action, and bolstered self-confidence among students (131).

Debra Harris Nixon and her students similarly describe how they delivered a required class on diversity at Nova Southeastern University. Collectively, the group sought to engender "an atmosphere of respect and acceptance thathonors every voice and does justice to the teaching/ learning relationship" (206). They did so by making a conscious effort to be intentional and present, embracing student ideas and contributions, creating a safe space for open and honest communication, dynamically sharing knowledge through the reversal of teacher and student roles, and using humor as a way to infuse energy and excitement into learning. Nixon and colleagues suggest that these conditions worked together to scaffold transformation (206-7).

A wealth of literature describes the pre-conditions for and benefits of interdisciplinary graduate classrooms that embody feminist pedagogical principles, which is perhaps unsurprising given the interlacing of feminist pedagogy and interdisciplinary knowledge (Hobbs and Rice, "Introduction" xix; Hobbs and Rice, "Rethinking" 139; Mayberry and Rees 69). For instance, Mary Jo Maynes describes her course on Gender, Genre, and Political Transformation in Germany and the Transatlantic World, in which she invited students from a broad range of disciplines to participate in a weekly virtual seminar, in-person meetings, and an online forum led by four faculty members across two US universities (118). Maynes suggests that this diversity led to high-quality student writing 
and theoretical analyses, including the generation of ideas that transcended disciplinary chasms (123).

At the University of Massachusetts Boston, Caroline Brown and Alexia Pollack collaborated to offer an interdisciplinary first year undergraduate seminar titled Examining Consciousness (A9-A10). They relied on varied sources including fiction, poetic prose, scientific articles, popular science essays, and personal writings to probe how the mind is constructed in both English literature and the "radically different ontological, epistemological and pedagogical perspective" of neurobiology (A11). Melding self-evaluation with various learning tools such as open discussion forums, oral presentations, in-class reflections, journaling, and formal essays (A10), Brown and Pollack propose that the unique way in which they delivered their course increased student engagement by attending to students' multiple needs, making abstract knowledge applicable, and transforming the classroom into a more relevant and accessible space (A14). They also argue that their course imparted various "metaskills" that are crucial to knowledge acquisition across a broad range of disciplines and life paths, including curiosity, immersion, resilience, persistence, and critical thinking (A14).

\section{Filling the gaps in the literature on feminist classrooms}

Although feminist pedagogy is configured in many different ways and in diverse university contexts, Nicole Seymour argues that the literature on these classrooms does not differentiate between undergraduate and graduate courses. For Seymour, certain critical queries - specifically, how these classrooms are initiated-are left unexamined (187-88). While others have aimed to elucidate the specific processes operating in their feminist classrooms using examples, Seymour notes that "the reluctance or refusal of feminist/radical pedagogy theorists to discuss this [initiation] stage . . . contributes to the sense that some believe it "just happens"' (193), when the process is likely "sought after and fought for" (194) by professors and students alike. Following a call for "realistic and progressive" feminist ethics (200), Seymour suggests that professors be candid about the initiation of these classrooms, as well as their implementation, without shying away from acknowledging the very real possibility of their failure. 
In addition to the limited discussion of process, few authors have explored student experiences within feminist classrooms in any depth; thus far, the primary focus has been on common teaching practices (Seymour 190). Despite feminist pedagogues' dedication to student empowerment and nonhierarchical structures and relations, we often know little about the learning process. What is particularly troubling for Seymour is that, in her review of publications on feminist classrooms, the majority are presented from the instructor's point of view and feature only sketches of student experiences without direct representation of their voices (190). Compounding this gap in the literature, instructors often have difficulty reliably assessing the learning that has taken place in their courses. Spencer attributes this to the "sleeper effect," which occurs when students do not realize how much they have learned until long after a course has ended (206). This renders midor end-of-semester course evaluations relatively useless, as they do not capture the potentially inordinate and ongoing transformative learning processes that students might experience. Without more solidly focusing on student experiences, the literature on feminist classrooms only tells part of an important story.

It is within the overlap of these three gaps (lack of initiation, student representation, and evaluation) that we situate this paper. In conceptualizing this paper, we wanted not only to describe a context from which others can consider their own present or future offerings of feminist, interdisciplinary classrooms, but to do so from a primarily student-centered perspective and one that traced the ways that the instructor mounted the course. The aim of this article is not to prescribe a pedagogic method, but rather to model the type of thinking that shaped our Becomings experience and to demonstrate the potential outcomes that can arise when each participant is empowered as an equal stakeholder in the learning dynamic. We sought to reflect on our entire learning process from the initiation of our cooperatively named Becomings course to its delivery and assessment. After our course took place in the winter of 2015, we engaged in both individual and collaborative reflection and assessment for nearly a year. We took great care to respect individual voices, encounters, bodily responses, and emotional reactions. 
A leap of faith: the instructor's reflections on the emergence of becomings

In order to situate our analysis and provide contextfor our Becomings course, we first provide the course instructor's reflections on pathways to designing and implementing the course:

Over the past few years, a number of graduate students within and outside of my department had been requesting advanced critical theory and methodology courses relevant to their research projects and areas of specialization. I witnessed how students and faculty who had trained in the traditional disciplines (psychology, sociology, and others) frequently debated the appropriate content of our programs' core theory and methodology courses, without finding clear resolution. This recalled for me my prior experiences as a doctoral student in Canada's first interdisciplinary gender and women's studies graduate program at York University, where, steeped in rich discussions about interdisciplinarity, I came to question whether standardized courses could meet my own and others' diverse teaching and learning needs, values, and interests. I graduated carrying with me many unresolved questions about the value and possibly the futility of trying to build a theoretical or methodological "canon" in a field premised on anticanonical interdisciplinary principles and approaches.

Reflecting on these past experiences, mindful of current debates about interdisciplinarity in my new home department, and considering my forays into critical pedagogical scholarship on the meaning of the concept, I approached my department chair with an idea that I had previously floated, unsuccessfully, as a graduate student: I would invite graduate students from across the university to join me in co-constructing and co-delivering an advanced theorizing course. As a long-time pedagogue who values innovations in teaching, he supported my bid to run the course as an innovative teaching experiment. This process was not without its bumps and challenges, which centred on faculty concerns about the rigor of the approach and questions about the appropriateness of experimenting with such pedagogy in an applied social science program. In May 
2014, I drafted a brief description of the course, and with my chair as champion, vetted it with my program curriculum committee. I then circulated it to all graduate programs across the college/the university. I met with potential students three times to build course learning objectives, assignments, grading schema, reading lists, and a presentation schedule. Course themes and foci emerged organically through these discussions; however, all acknowledged that taking the course required a leap of faith that we would each achieve our learning and teaching goals while still meeting or exceeding university requirements for rigor in graduate-level courses. Given the culture of concern about maintaining standards that permeated my department, questions of rigor and relevance haunted me throughout this process. Yet in reflecting on my experience and in reading course evaluations, it has become clear to me that this approach was critical to meeting each student's learning needs (as varied as eighteenth-century English working class women's poetry and twenty-first-century masculinities), while still encouraging the intellectual growth and development of those who had entered the course with some prior content-related knowledge and experience.

I found co-constructing an interdisciplinary theory course with graduate students to be the most powerful, and challenging, teaching and learning experience I have had in my career to date. The process allowed for the uniqueness of each participant as learner and teacher to emerge organically as we took turns stepping up and down from the podium. This process also enabled us to cohere as a provisional community in an intensely competitive environment as we cooperatively worked through blockages and found pathways to understanding the mutually decided upon, yet theoretically dense, material. Students from the course have reflected deeply on their experiences as teachers and learners and emphasized the learning that happened for them. I, surprisingly, accomplished what I had sent out to do: I let go of my role as expert and opened myself to listening and learning from the significant knowledge, experience, and ways of knowing that surfaced in the class. However, this was not without a melancholy-the melancholy of defrocking myself of the power of expertise, of acknowledging that the empress has no clothes. Yet rather than feeling exposed by this disrobing, I felt freed by it.

\section{Data collection}


During the last class, each class participant engaged in a "free fall" writing exercise in which we wrote about our personal experiences of teaching and learning throughout the semester. This exercise fueled our desire to share our experiences with other feminist and critical academics and, ultimately, to write this manuscript. As we shared our free fall writing, we realized we had uncovered common themes and generated compelling questions related to the learning process that we wanted to investigate further. At a follow-up meeting, we developed the following questions that each studentauthor would later respond to in written, narrative form: (a) what was your experience of emotion in the classroom and what was it attached to?; (b) what conditions enabled/inhibited your learning?; (c) what is your definition of learning and how has it changed?; and (d) what does this experience mean for you moving forward? We assembled both the free fall exercises and narratives - which ranged anywhere from around three hundred to a thousand words-into a single document. This document constituted our data and was composed of writings from each student-author and an additional classmate.

\section{Contributors}

In addition to the seven authors, one additional classmate contributed to our data. The seventh author is a full professor in the Department of Family Relations and Applied Nutrition at the University of Guelph. At the time of the course, all others were graduate students (two masters and six doctoral): four in the Department of Family Relations and Applied Nutrition, two in the Department of Psychology, and one in the School of English and Theatre Studies. We occupy distinct and overlapping social, economic, and cultural locations. We claim various ethnoracial identities (though all have light-skin privilege); two of us are immigrants (one from a former colonizer nation in the Global North and the other from a formerly colonized one in the Global South); five identify as having working-class roots; each identify as women; are variously mentally and physically dis/abled; identify along a spectrum of sexualities including heterosexuality and queerness; have experienced different degrees of body privilege and oppression; and vary in age from twenty-four to fifty-four. We are also influenced by various theoretical backgrounds and perspectives (e.g., poststructuralism, new 
materialism, postcolonialism, and critical and transnational feminism). These various and intersecting personal, social, and academic identities came into play during the course and in our data analysis in both subtle and explicit ways, informing in-course conversations, our reading of the literature, and how we approached this paper.

\section{Data analysis}

As we ourselves were participants, it was particularly important for us to use a method that acknowledged our relationships to the material and to each other. Thus, we analyzed our data using Kathy Charmaz's version of grounded theory, which has roots in interpretative, constructionist, and phenomenological traditions ("Grounded Theory" 31). We decided that the static themes obtained using thematic analysis would not allow us to fully capture the dynamic, temporal, and unpredictable aspects of our experiences. Grounded theory, in contrast, let us more thoroughly implicate process because it "[blurred] the often rigid boundaries between data collection and data analysis" (Charmaz, "Grounded Theory" 28), which was useful given our dual roles as participants and researchers. In constructionist grounded theory, researchers are tasked with interpreting participants' experiences and construct meaning in interaction with their data and participants (Charmaz, "Methodology" 6398). Constructionist grounded theory emphasizes reflexivity about researchers' and participants' assumptions, interpretations, and subjectivities (Charmaz, "Methodology" 6397).

We began by independently examining and coding the dataset. As suggested by Charmaz ("Grounded Theory" 43), we focused our coding on processes, actions, and consequences (e.g., transformative learning) rather than on topics or themes (e.g., feminist theory). Over several group meetings, we read and discussed our codes, compiled them into a large list, and organized them into like groups by writing them on large sticky notes and physically rearranging them. Although we attempted to stay close to our words as participant-contributors, at times we expanded upon our own experiences and further interpreted our own and others' narratives. Thus, we analyzed and categorized the codes at both an "in vivo" level, in which the analysis was grounded firmly in the data, and a more theoretical level based on our interpretations as 
researchers (Charmaz, "Methodology" 41). Once we had sorted all the codes, we defined and named the broader conceptual categories by discussing the properties, conditions, and consequences of each and the relationships between and among them (Charmaz, "Grounded Theory" 45).

In producing our broader theoretical categories, we also developed a metaphorical model — that of the water cycle — to help conceptualize and explain our categories. This enabled us to more clearly see the process of learning. We then checked our analysis by rereading the dataset and discussing whether our original categories had remained true to the data. The second author used our group analysis and discussions to begin building our theoretical story and writing accounts of the finite yet fluid processes that comprise the continuous movement of water and make up the water cycle metaphor. We used these accounts as a basis for the analysis section of this paper. In keeping with the grounded theory method, only after this process was complete did we engage more deeply with the extant literature on critical and feminist pedagogies and make linkages with our data.

\section{Results}

In the following section, we detail what we see as the "results" of our analysis. Much like the course itself, we outline our results and analysis more fluidly than traditional outcome-oriented analyses of group processes and outcomes. In describing our water cycle of learning, we highlight the power and context that shaped our interactions and how we negotiated them; the emotionality, vulnerability, and difficult knowledge the course precipitated for us; the freedom and frustration of learning together; and the transformations this course has sparked for us. We use quotations from our narratives to share our voices in relation to the water cycle we theorize, and we explore the challenges and beauty of becoming. Throughout the results section, however, we refer to ourselves numerically, in order to respect our identities and disclosures in reflecting on the course. 1 We present a diagrammatic representation of our

\footnotetext{
${ }_{1}^{1}$ Numerical labels do not correspond to authorship order.
} 
water cycle in Figure 1 and describe it below.

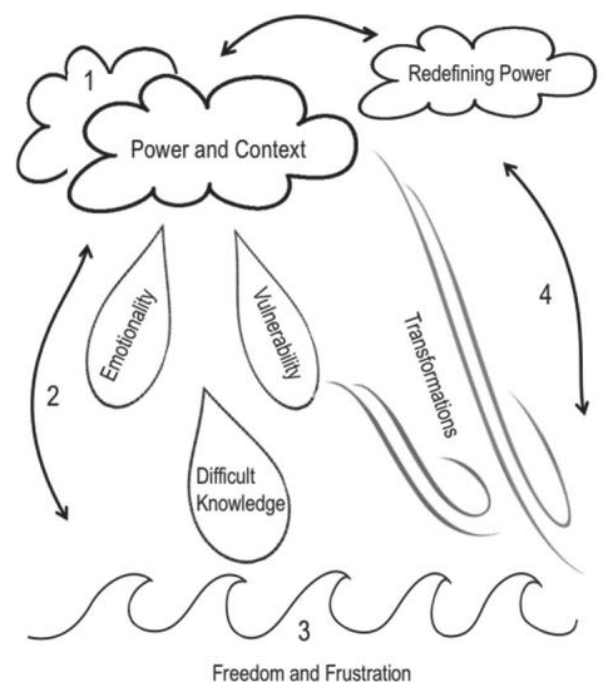

Figure 1. Visual representation of our results as a water cycle

Water: seeping ... permeating ... mutating . . becoming

Water is essential for life. According to the United States Geological Survey's "Water in You" webpage, water constitutes 60 percent of the human body and 73 percent of the human brain. It was a corporeal, affecting, one might even say water-born, idea for us to equate the pedagogic experience of becoming with the water cycle, a process in which our water-based minds and bodies were inextricably linked and mutated. Now, some readers are no doubt anticipating an account of some existential epiphany; well, hold on to the epiphany part because that does express the impact of our learning. But existential? No, this course was not about disorientation in the face of a meaningless world; from its inception, Becomings was a course rooted in real-world perspectives and the pedagogic environment was a response to the conventional delineations and power constructs of teaching and learning.

The clouds: water as a collection of highly charged particles of power and context

Despite the different research focuses, disciplines, and worldviews among each of us in the room, the respect, support, and intellectual stimulation shown by each 
colleague demonstrated the power of collegiality and ethic of care that humbled and inspired me.

\section{-Contributor 6}

Typically, gender studies is positioned as a discrete domain, or it is accessed via specific subject routes such as sociology, psychology, or linguistics. We all shared a number of questions, however: What would happen if we put those subject boundaries to one side? What would happen if participants each had different subject specialisms? What type of learning could interdisciplinary work facilitate? Our introduction to the course was a tantalizing email, circulated to all graduate program coordinators by the instructor: "This is an opportunity for students ... to come together to collectively design the course and participate in teaching and learning, based on theoretical and methodological interests. Basically, we create the course, approaching the experience as an experiment in critical pedagogy and . . . in how to support each other in defining/developing/fine tuning our theoretical and methodological directions (including mine). We'll each be teachers and learners in this course." The universality of the invitation to participate was the first step in breaking down the usual subject boundaries; just like the range of particles in a cloud, students with backgrounds varying from family and kinship, sexuality, and embodiment studies to literary studies responded to the call.

Assembling the students, or the metaphorical particles, was just a start; the true potential lay in the charged encounters, the bumping together of those particles to create reactions. The conventional hierarchy of instructor and students had to dissolve. As the email suggested, this course was about coconstruction, a process in which power (and consequently responsibility) was not vested in one person but in all. The pre-course meetings - for exploration and planning — were driven by the ethic of co-construction. In these meetings, participants voiced their intellectual aspirations, their personal substantive foci, and the formal study criteria they were required to fulfill for their respective programs and/or for their sense of personal growth and accomplishment. A mutual regard for the charged idiosyncrasies of each person remained of paramount importance; in this way, we did not allow the potential constraints of bureaucracy to 
dominate (though they did haunt the discussions). Rather than consider how the course could be framed to fit into the protocols of the university, we gave priority to questions, ideas, and academic resources. Each person then considered how their study criteria could be mapped against the course syllabus and graduate program requirements. Creating flexibility in protocol was not about abandoning academic rigor but exploring our shared and unique academic and personal goals together. Co-construction was a flexible process, but each person still held onto the tenets of ambitious learning and progress, structuring their own routes toward measurable outcomes.

Of course, it would be naïve to think that a group of complex individuals with varying political and emotional investments, diverse scholarly interests, and fluctuating subjective dispositions could just turn up in a seminar room to study material that was contentious, provocative, and emotionally taxing. Subjectively, each participant envisaged that a shared ethic of care and sense of community would help us to navigate the inevitable discomforts and conflicts that would arise in the classroom. We planned not only for the mind but also for the body and soul; we openly addressed individual needs for accessibility and comfort. By recognizing how the water-like knowledge of Becoming could seep and permeate in unforeseen and perhaps disturbing ways, we collectively acknowledged —even expected — that uncomfortable responses could and would arise. As Contributor 2 described: "I felt the most frustrated when reading the work of Judith Butler. I was annoyed that her writing was so difficult to read. After many hours of struggling to read her work, I felt as though I had a basic grasp of her arguments. I felt confident in participating in class discussion. In this case, I misread what was meant by Butler and was brutally shot down by other class members who stated that I was incorrect. This caused me to become less vocal in future classes and led to more frustration. So much so that I contemplated dropping the course but did not do so due to pressure from others to stay. I also began to feel a sense of community with a couple of others in the class who also confessed to not fully understanding the readings." Acknowledging discomfort-even distress - we tried to remain willing to engage, invest ourselves in the process, and trust that the collegiality of the group would support and accept any return on the investment. Though there were moments where we each felt unacknowledged, shut down, or lost, we each returned week after week to explore the sometimes murky waters of 
Becomings.

Precipitation: droplets of emotionality, vulnerability, and difficult

knowledge

I began to feel as though learning is becoming: a better student, a better feminist, a better human being. It is ongoing, ever-changing, and unending.

-Contributor 5

The coalescence of charged particles was, in many ways, an inevitable outcome. The downpouring of insights revealed vulnerabilities and strengths that were manifested in both tropical storms and refreshing showers; as Becomings took shape, the comfort of enacting a more democratic relational space was, at times, challenged by the discomfort of daily reality.

The theoretical material for Becomings was absorbing and challenging. Rather than remaining tethered to any particular, institutionally inscribed canon of feminist literature, we selected a corpus of works by those whose writings have challenged, inspired, and perplexed us (see Appendix²); theorists such as Judith Butler, Nicola Gavey, Elizabeth Grosz, Rosi Braidotti, Karan Barad, and Gail Weiss are not simple reads. We saw the benefit of interdisciplinarity in the diversity of the syllabus. With different subject domains in play, learners had to process different knowledges in addition to the core materials-knowledge that was difficult, troubling, and invigorating. On one occasion, a short story proposed by one classmate with a background in literature proved to be inaccessible, even troubling, to others. On other occasions, the different knowledge domains were potent and successful forums for evaluating theoretical concepts and

\footnotetext{
${ }^{2}$ Although we have included a full copy of the finalized course syllabus, constructed by the studentauthors and instructor, we feel it is imperative to note that the inclusion was made in order for readers to contextualize Becomings and not to act as a prescriptive tool for future offerings of feminist classrooms. The syllabus includes a description of the course, a list of learning objectives, a summary of course assignments, and a full list of readings; however, there existed a fair amount of fluidity and adaptiveness to accommodate for the diversity of interests, program requirements, personal learning objectives, and accessibility needs.
} 
reaching new understandings. For example, one colleague's digital knowledge proved helpful in providing a new forum in which to examine and process the work of Elizabeth Grosz. Above all, the pairing of theory and different contents created vibrant critical discourse that was both challenging and contradictory, yet enlightening and empowering. Standing in the rain was not about doing feminism but immersively experiencing feminism; as classmates reflected, it was about throwing the "rule book out the window" and absorbing a personalized feminism.

To position Becomings purely as an intellectual engagement with drops of difficult knowledge would be a fallacy; the momentum of precipitation varied and the splashes of rain brought sensations of emotionality and vulnerability. In all of our planning, in all of our due diligence regarding needs and identities, we did not fully anticipate the subtext of the theoretical material. Emotionality varied; comments such as "emotional presence and energy in the room dictate the degree to which my weekly headache develops" (Contributor 1) and "I started to notice that on most class days a sense of anger or crankiness would come over me unexpectedly" (Contributor 2) reflect the impact. A further comment from Contributor 1 reveals the potency of the unexpectedly physical engagement: "being in a space that was not always comfortable and allowing that discomfort to itselfbe the learning was a curious encounter with the body." The rainstormand, at times, it was a storm - was unavoidable as the effects of theory and content struck different resonances with each classmate. Emotionality was felt bodily and spiritually; as the rain fell, we were more permeable than we realized.

Acknowledging vulnerability acted as the remedy for the sometimes overwhelming saturation of mind and body - this acknowledgment was crucial to the ethos of Becomings and was derived from the evolving sense of mutual empathy and acceptance. The force of the knowledge downpour dislodged the usual boundaries of inner and outer self and we recognized the significance of turning the inside out. Permitting ourselves this inversion evolved as we witnessed others set different precedents for engaging and sharing from a place of personal experience and vulnerability. We embedded implicit permission for public introspection within our learning culture. Both fragility and durability emerged within the discourse of vulnerability: 
shutting down, restarting, taking risks, questions of competency and disclosureBecomings watermarked us all.

\section{Accumulation: water rivulets of freedom and frustration}

This collective process of creating something that was meaningful for both self and others was an incredible launch pad ... tapping into my curiosities, and expanding my theorizing abilities inside and outside of my discipline."

\section{-Contributor 7}

Ideas collected first in puddles, then grew into ponds and lakes; water was overflowing, knocking against the side of the tank of the university, beautiful yet perilous, forceful. To a great extent, the peril was assuaged by communication. Critical and theoretical concepts require the language of academia, lexical fields in which terms are contained and defined; abstractions of knowledge are explained and analyzed familiarly within referential, propositional, or ideational frameworks. Communicating the potency of Becomings demanded more than academic terminology could achieve. What emerged was a consistent requirement for plain and non-moralizing language as a bridge between our inner and outer selves, and between contributors; the absence of hierarchy in the learning dynamic created the space for this plain speaking. Our early interactions, fraught as they were with hesitancy and inquisitiveness, revealed the vulnerability involved in entering into a new learning space, even one designed to be inclusive and feminist. As time progressed and the water cycle of learning became more familiar, we became more assured, reflecting our newfound engagement with Becomings and how the theories we studied held implications across different substantive topic areas.

The perilous effects of our collective understanding were juxtaposed against the beautiful yet forceful experience of our insights. The combination of ideas and emotions created a flood that both threatened and carried us. Navigating these floodwaters was a newfound skill and one that facilitated and generated new lines of inquiry, refined analyses, and nurtured self. 
Evaporation: transforming insight into new encounters with becomings

Happiness in feeling my brain stretch in all the right ways, at peace with holding tensions in my mind and in my research and a release of some of the tensions I had been holding onto and struggling with as a critical researcher who straddles both the quantitative and qualitative worlds.

\section{-Contributor 6}

Evaporation, the inevitable outcome: the final stage of the water cycle was both corporeal and collective. Becomings was an embodied adventure-a challenging, transformative, and often surprising encounter with theory. From the outset, we sought to challenge power hierarchies by coconstructing our critical feminist theory course, all the while acknowledging that power and context would necessarily shape our encounters. Indeed, we positioned difference in a positive way, allowing it to pull us in new directions in our own and collective understandings. As Contributor 6 reflected: "I have often wondered where I fit and which perspectives make sense to me both personally and as a researcher ... of late I have found myself struggling to situate myself between research worlds that often seem disparate. This course has allowed me to be more comfortable being in that space."

Of course, building a space where emotionality is welcomed also opens space for us to be affected, and not always in comfortable or easy ways. However, these disruptions, too, might be configured positively in the unique learning opportunities and the way that they shifted our subjectivities: Contributor 7 suggested, "Even when tired, frustrated, and overwhelmed, my learning was not inhibited. Perhaps for the first time in all of my learning contexts, I was permitted to speak as a whole person." Contributor 6 also noted, "For me, going through these emotions was the learning experience. I do not think that I would have grasped the material otherwise. I have gained both an understanding and a respect for these emotional processes as learning tools and this has changed my definition of learning - I have come to appreciate that learning is not only engaging with the material intellectually but also emotionally and experientially." 
Despite our intentions of building a safe-as-possible space to take risks with theory, we cannot ignore that what happens within classrooms has ramifications for our academic and personal lives beyond the classroom setting. As such, some class members expressed worry about whether their reading of theories would be considered "right" or "wrong" by others inside and outside of the classroom. For example, Contributor 3 revealed: "I saw myself as outside the group because I had such a different, and more traditional, sense of female sexuality and feminism; I had the sense that, somehow, I had got it wrong." In addition, Contributor 4 expressed: "I felt that I was not meeting some arbitrary expectation of learning, and feeling unintelligent is a very uncomfortable feeling for someone whose identity is so wrapped up in education and intelligence."

Exploring accessibility in the classroom meant understanding that we all have intellectual, emotional, and physical limits-additional shores creating boundaries around our water cycle. Both knowledge and physicality in classroom spaces challenged us to transform. As we have theorized, frustration with these limits has also, in a way, scaffolded freedom in the sense that exploring our discomfort has led many of us to better understand how we move in and beyond academic spaces. This is illustrated in the following reflection from Contributor 4: "I have come to think of the course as having been a medium for 'meta-learning,' where I went through a process of learning to learn and learning what learning can look like ... It was . . . a very liberating experience because I realized that I did not need to meet anyone else's expectations of learning." Similarly, Contributors 3 and 7, respectively, noted: "My life is a series of opportunities and constraints. I define myself; I am defined. I declare myself; I am judged. I know myself; I am socially constructed" and "What I needed to be most mindful of was how frustration and fear can feed feelings of insecurity and incompetence, which can lead to me to question my right, merit, capacity, and ability to be in this learning space and hijack my engagement and love of learning."

The main water cycle operated as a weather system throughout the course but within that main system there existed mini weather patterns of varying durations and force. These mini patterns gave each classmate the possibility to join the cycle at different points depending on factors such as individual research topic, position in the rational/emotional 
dynamic, and the pace at which one "cycled" through each stage. In whatever form, Becomings was waterborne; new perspectives formed the cloud base of the next cycle. As time passed, those cycles became self-perpetuating, informing, challenging, and enhancing to create a collective becomings and personal becomings. The individual and collective moments of elucidation and disruption, as well as the constant grappling with affect and theory, are experiential elements that continue to percolate after the course has closed. Contributor 7 noted, "I developed confidence in my competency to consistently be in motion and know that I will never arrive. I am in the process of constantly arriving to old ideas with different perspectives, and to new ideas with openness and critical thinking. Perhaps more in line with the spirit of this course I am okay with constantly becoming." Contributor 1 reflected, "It has meant an even deeper rift between my way of knowing and being and the academic environment in which I am entwined; this is not always comfortable, but more in a minded sense: it has become even more challenging to 'follow the rules' of academia when my body and becoming pulls me sharply in the opposite direction and encourages me to embrace my inner vagabond." And Contributor 5 wrote, "For the first time along this graduate school journey, I feel as though the theoretical frameworks that I cite within my work are not simply relegated to words on a page, but rather, are becoming integral to my personhood. While I am certain that I will continue to experience moments of dissonance throughout my life, I found the slightest bit more harmony between the researcher and human being that live within me." In analyzing the narratives we wrote on the last day of class and in reflecting on our experiences since that time, many of us have noted that the value of the course has emerged much more clearly now that we have left the intensity of the feminist classroom we created.

\section{Discussion and Conclusion}

In addressing concerns by scholars like Seymour, we have shared our processes of course construction and focused on how students felt about the course by including our own voices as scholar-researcher-teachers in our exploration of the water cycle metaphor we built. We brought together graduate students and a professor with a shared interest in exploring feminist theory deeply and differently; as Don Locke and Mark Kiselica suggest, scaffolding transformation relies on collaborating as a community of student- 
teacher learners, from syllabus construction to honoring diverse positionalities (qtd. in Nixon et al. 207). Our collaborative learning culture was rooted in the safe engagement principles identified by Leland Spencer mentioned above $(203,208)$.

Much of the intensity of the classroom context that precipitated our water cycle of learning was built in from the outset. The corpus of works that we assembled reflected our academic diversities; consequently, the texts were more varied than those often seen in a feminist classroom, a textual range validated by the ideas of Hobbs and Rice ("Introduction" xix; "Rethinking" 139), and Mayberry and Rees (69). In the spirit of openness and collegiality, we encouraged ourselves to take risks with theory, to enter into the literature, and to acknowledge our frustrations and resistances rather than pretending they were not present. Our course also provided us with access to theories and substantive topic knowledge that we might not have otherwise considered. Configuring difference positively —as "a productive location to start from" (Braidotti 98)—allowed us to work with and through our bodies and spaces of belonging in a way that grounded our theoretical discussions in more than the abstract and esoteric. The evolving sense of mutual empathy and acceptance described above stemmed in part from the leaky space we configured as we deconstructed boundaries (Shildrick 3 ) and actively brought body and mind into the classroom, unlike the conventional separation of "reason from feelings" (Martin 81). Our other spaces of belonging beyond our disciplinary cultures also shaped our interactions, contributing to the affect that characterized the classroom space.

Like the water cycle we theorized, we consider our course to have been a beautiful cultivating space for individual and collective accumulation of knowledge, both substantive and bodily. Water, however, is also dangerous: we often experienced tensions and resistances as we explored challenging content together. As Clare Hemmings notes, "feminist groups are difficult and complex spaces, as we inhabit relations of power at the same time as we attempt to negotiate them" (302). Mindful of Shrewsbury's references to the "autonomy of self and mutuality" (12) and the need for "participatory and democratic" (13) processes, we attempted to navigate power relations within the classroom space by being transparent and open. We have since continued to explore some more tacit power dynamics that may have impacted our interactions, 
though the evaluation of these power dynamics requires further research. In the meantime, we can offer certain observations.

Power circulated along advisor-advisee, teacher-student, Masters-PhD, discipline, age, perceived knowledge, conventional-countercultural, and other lines as we interacted; to ignore these dynamics would have been to miss a key aspect of the way our water cycle flowed. The power relationships were, at least in part, inscribed by forces external to (though interpolated with and inextricable from) our classroom-for instance, the pressures to ensure that the course was rigorous and relevant as well as the need for grades to be awarded at the close of the class and the fact that one person would be charged with awarding these grades. These external power dynamics were, in a way, easier for students to navigate: we spent a significant amount of time negotiating which form of grading would work best for each student, for example. The subtle articulations of power that flowed through the classroom space were more challenging. Perceived knowledge operated as we attempted to take risks with theory; class members came into the course with different experiences of the hierarchized world of academia and with various levels of confidence in their knowledge of theory. Analyzing our narratives and constructing this paper has itself challenged us to continue to explore the intertwined nature of internal and external power: for example, how institutional experiences and constraints shape our subjectivities and interactions. Being vulnerable in a context where we are frequently asked to be experts is no easy task, and it invokes an idiosyncratic response that cannot easily be theorized. Future research could focus on the subjective and objective responses to the interface of internal and external power.

Inviting body and mind into the classroom meant also acknowledging, in our reflections, how disembodied classrooms can be; as a tidal current pulls and sweeps in unpredictable ways, so, at times, we were caught unaware by the watery momentum of mind and body interactions. A feminist classroom is not a utopia, but a space of acknowledging that, despite our best efforts, we are destined to fail. In the face of these "failures" we learn still more about our own and others' differences. This acknowledgment of "failure" moves us away from the traditional academic spaces discussed by Martin in which reason and feelings are separated (81). We all shut ourselves and others down; we 
all have different needs and desires. At times, these needs and desires conflict with the reasoning process. Rather than seeing this as a negative, our water cycle allows for the accumulation of rationalized and felt learnings, negotiated through difference, as effective ways of being embodied in the classroom. Understanding the tidal pull of embodiment is a process in which we are still engaged. Future research or learning experiences will need to carefully examine those holistic tidal patterns to sustain a smooth pedagogic passage.

Perhaps the greatest testament to our experience of Becomings is the enduring influence it has provided in our professional and personal considerations; the incomplete reflections on some aspects reflect the ongoing momentum of the water cycle and the durability of our experiences. Unlike Spencer's discussion of the "sleeper effect" (206)—which he categorizes as the "vexing" (206) question of students' delayed self-awareness of their learning - the culture and dynamic of our environment facilitated an ongoing recognition of the ways in which we were impacted. Still, many of these insights have percolated and developed since the course concluded, including in the construction of this paper. By enabling our whole selves to participate, we were and remain very conscious of the educational potency of Becomings in enlightening, informing, and transforming self. This leads us to wonder about the time needed to absorb theoretically difficult, affect-imbued ideas and how students and teachers might make room for the oftentimes unpredictable and protracted temporalities of learning in a neoliberal context that privileges breadth over depth, speed over circumspection. At the very least, we suspect this might involve "letting go" of the need to master texts and, instead, embrace the struggle to grasp new theoretical concepts and respect the time and concentration required to think outside the "what is" of established practice.

Our course, like all others, is embedded in a context that does not always-or even often-acknowledge difference and let affect in. Within the context of the neoliberal university, which is oriented toward turning out professionals able to contribute to national and international economies, we often find ourselves at a loss for how to embody feminist praxis as we seek to learn and work in ethical and compassionate ways. Prescribing a solution to this dichotomy has never been the purpose of this article; narrating our experience of Becomings is intended to activate a recognition of difference 
and reveal that, at times, Becomings felt like a bubble of feminist pedagogical praxis, a space in which our bodies and emotions were honored and deemed equally important to our learning as the substantive theories that we attempted to grasp. While not without its own challenges, the transformations sparked by this course will help us move forward with intentionality as we continue on our learning journeys. In many ways, the power of the course lies in its explicit acknowledgment of power dynamics that often go unmarked, both in and beyond our classroom. This acknowledgment and our interactions precipitated emotionality, vulnerability, and difficult knowledge. While our encounters with each other, body and mind, were not always comfortable - and were indeed often frustrating - there is a certain freedom associated with allowing for a pooling of collective experiences. We were indeed caught by the staggering impact of Becomings: during and since the course, we have acknowledged how learning feminist theory differently has transformed us not only in terms of accumulating knowledge but in substantial shifts in how we know ourselves as people.

\section{Appendix}

FRAN6200 Syllabus | Research Topics in Family Relations and Human Development | Becomings: Emerging Directions and Critical Dialogues in Gender, Sexuality, and Human Development

In this course, we engage with emerging directions and critical dialogues in the inter- and transdisciplinary study of gender, sexuality, and "human development" (broadly defined). By collectively determining course topics and evaluation methods, we center professor/student collaboration in innovative ways that open space for maximum teacher/learner engagement in curriculum development and delivery. Fusing critical pedagogy, methodology, and theory, the course provides a unique opportunity for students to become closely acquainted with important new directions in theory and to gain greater familiarity with emergent and creative methods for understanding and appreciating the vast diversity of human experience. Emphasis will be placed on student research interests, on gender and sexuality theory, and on emergent notions of human development as becoming. 
This is an open topics course. Based on the interests of those who came to our organizing meetings, held on October 30th, between 12:30pm and 2:30pm, Nov 27th, from 9am to 11:30am, and on December 18th, we together decided on course themes, determined readings, established the learning objectives of the course, and developed assignments and evaluation criteria.

\section{Areas of theoretical and methodological exploration are as follows:}

- Theories of Gender, Sex, Sexuality, the Body, and Embodiment, including Performativity Theory, The New Materialism, Body Becoming Theory and Posthumanist Studies

-Self-Other Relations, Encounters with Difference, and the Question of the Posthuman

- Intersectional Approaches in Theorizing and Research

-Sexuality, Sexualization, Sexual Identity, Desire, and Pleasure

- Critical and Feminist Pedagogy and Theory

- Time, Memory, and Futurity

- Emergent and Creative Approaches to Research and Knowledge Mobilization

This course will start in January 2015, running for twelve weeks on Thursdays from 4:30pm to 7:20pm. Enrollment is limited to twenty-five students. Masters and doctoral students from within the college and across and beyond the university are eligible. For more information and to enroll, please contact the course professor.

\section{Learning Objectives}

1. Establish a critical appreciation of contemporary feminist-informed gender, sex, and sexuality theory, theories of embodiment, materialization, and body management, as well as critical pedagogy and posthumanist theory

2. Develop an understanding of key aspects of various frameworks (e.g., performativity, embodiment, new materialism, body becoming theory, sexuality theory) and how these might be used within critical feminist scholarship/praxis 
3. Apply at least two theoretical frameworks (e.g., new materialism, body becoming theory) in student and instructor areas of research interest to clarify how theory can be brought into analysis and practical application (e.g., interpreting and evaluating literary texts, designing research studies, interpreting data, and performing psychotherapy)

4. Critically engage with texts introduced by developing a collection of reading notes and reflections on materials as students and instructor progress through the course, adding insights from class members following discussions and treating reflections as a dynamic exploration of theory and its implications for methodology and interpretation

5. For those interested in digital technologies, engage in a "hands-on" examination of course and other texts (literary texts and research data), and through an interactive mode (blogging, digital storytelling) to understand how digital tools can reveal new meanings

6. "Take risks" and experiment with theory by engaging in lively and respectful class discussion around how theory can be applied to our diverse topic interests to enrich and nuance student/instructor understandings of texts and lives

7. Integrate theory-work introduced in the course and identify how this theory might help to fill gaps in prior theorizing around gender, sex, and sexuality development, subjectivity, identity and difference, body practices/management issues, embodiment/materialization, and the posthuman

8. Develop proficiency in collaborative student-led inquiry, including cooperative curriculum development and course delivery and collective determination of types of assignments and assessments

Course Assignments and Assessment

Presentation and Critical Reflection of Selected Texts - 2at35\% each(20\% presentation, 15\% written reflection)

Over the course of the semester, students and instructor will engage in a deep reading of two major theoretical texts introduced in the course. For each, the student or 
instructor will develop a presentation of the key ideas introduced in the text, their interpretation of the text, and its applicability to their main area of interest (sexuality development specifically focusing on virginity, sexualization, or body management practices, for example). Each will identify areas where they feel that their understanding could be enhanced and develop questions to pose to the class during their presentation. Students or instructor will circulate the questions at least two days prior to the presentation to allow peers to reflect on them prior to class time.

Prior to or following presentations, students will prepare a written reflection on the chosen reading, focusing on the following: main theoretical ideas presented, their interpretation of the text, how it can be applied to their area of interest (e.g., sexualization, body management issues, gender in nineteenth-century Anglo women's poetry), how/if it expands upon their prior knowledge of gender, sexuality, and embodiment, and questions that remain. Students may choose to solicit comments about their presentation by asking the group to identity i) what they, in their role as scholar/instructor, did well and ii) what they might want to unpack or develop further. Following the presentation, they will integrate insights generated through class discussion into their written reflection (which should be at least fifteen hundred words).

Engagement-30\% (15\% engagement in discussion plus 15\% engagement with readings through a reading log, through reflective comments posted in an online interactive mode, or through a digital story that animates the theory)

Throughout the semester, students will complete a collection of reading notes to foreground their participation in class discussions. They will develop an outline for their reading log with the following sections: key theoretical ideas, tensions between/contributions to other course readings, questions remaining/knowledge gaps. Following in-class discussions, they will revisit their notes, reflect on how discussions have helped to fill gaps left following their reading, and/or note any additional questions raised.

Rather than complete a reading log/ notes, some students may choose to post their reflective comments in an interactive mode online, either in discussion format via 
Courselink or a blog. Alternatively, those interested in digital storytelling might opt to develop a digital story that animates and explicates the theory introduced and their reflections on/applications of it.

In class, students will commit to engaging in open and respectful discussion with peers about sometimes difficult readings that may be interpreted differently based on each class member's social location and areas of interest. For students and instructor, part of this engagement will involve avoiding monopolizing conversations and being sure to engage in active listening rather than always talking.

Reading List

January to April 2015

Introduction

WEEK 1: January 8th, 2015

Terms of Engagement: Critical and Feminist Pedagogies

Required:

Britzman, D. P. (1998). "That lonely discovery”: Anne Frank, Anna Freud and the question of pedagogy. In Lost subjects, contested objects: Toward a psychoanalytic inquiry of learning. (pp. 113-135). SUNY Press.

do Mar Pereira, M. (2012). Uncomfortable classrooms: Rethinking the role of student discomfort in feminist teaching. European Journal of Women's Studies, 19(1), 12835.

Robertson, K. \& Zlotnick, S. (2010). Putting class back in the women's studies curriculum. Feminist Teacher, 20(2), 95-110.

Kishimoto, K., \& Mwangi, M. (2009). Critiquing the rhetoric of "safety" in feminist pedagogy: Women of color offering an account of ourselves. Feminist Teacher, 19(2), 87-102.

Knoll, K. R. (2009). Feminist disability studies pedagogy. Feminist Teacher, 19(2), 122-33. 
Section 1: Language, Gender, Power: An Introduction

WEEK 2: January 15th, 2015

The Linguistic Construction of Sexed Identity

Required:

Butler, J. (1993). Bodies that matter: On the discursive limits of "sex." New York and London: Routledge.

Preface, pp. ix-xiv Introduction, pp. 1-23

Chapter 1: Bodies that Matter, pp. 27-56

Chapter 2: The Lesbian Phallus and the Morphological Imaginary

WEEK 3: January 22nd, 2015

The Linguistic Construction Of Gender Identity

Required:

Butler, J. (1990). Gender trouble: Feminism and the subversion of identity. New York and London: Routledge.

Preface, pp. ix-xiv

Chapter 1: Subjects of Sex/Gender/Desire pp.1-34

Chapter 3: Subversive Bodily Acts, pp. 128-41 (iv. Bodily Inscriptions, Performative Subversions)

Conclusion, From Parody to Politics, pp. 142-49

Recommended:

Baker, P. (2008). Sexed texts: Language, gender, and sexuality. London: Equinox.

Introduction, pp. 1-23

Chapter 2: Accounting for Difference, pp. 29-50

Chapter 3 Doing Gender: Community and Performativity, pp. 72-89

Salih, S. and Butler, J., (Eds.). (2004). The Judith Butler Reader. Blackwell Publishing. Introduction, pp. 1-17

WEEK 4: January 29th, 2015

The Linguistic Construction and Deconstruction of Masculinities

Required:

Atkinson, M. (2011). Deconstructing men \& masculinities. Toronto: Oxford University Press.

Introduction: Masculinity in Crisis?

Chapter 1. Men, Power, and Pastiche Hegemony 
Chapter 3. The Lost (and Found) Boys

Chapter 6. Mass-Mediating Risk Masculinities Chapter 7. The Unbearable Whiteness of Being

Recommended:

Reeser, T. W. (2009). Masculinities in theory: An introduction. John Wiley \& Sons.

Introduction, pp. 1-16

Chapter 1: Theorizing Masculinity, pp. 17-54 Chapter 2: Social Masculinity and Triangulation, pp. 55-71

Chapter 3: Sexing Masculinity, pp. 72-90

Chapter 4: Theorizing the Male Body, pp. 91-118

Connell, R. W. (2005). Masculinities (2nd Ed.) Berkeley: University of California Press.

WEEK5: February5th, 2015

Undoing Gender

Required:

Butler, J. (2004). Undoing Gender. New York and London: Routledge.

Introduction: Acting in Concert, pp. 1-16 Chapter 1: Beside Oneself: On the Limits of Sexual Autonomy, pp. 17-39

Chapter 2: Gender Regulations, pp. 40-56

Chapter 3: Doing Justice to Someone: Sex Reassignment and Allegories of

Transsexuality, pp. 57-74

Chapter 4: Undiagnosing Gender, pp. 75-101 Chapter 9: The End of Sexual

Difference?, pp.174-203

Chapter 10: The Question of Social Transformation, pp. 204-31

Chapter 11, Can the "Other" of Philosophy Speak? pp. 232-50

Section II: Embodiment, Sexuality, and the Body Becoming

WEEK 6: February 12th, 2015

Embodiment and ldentity

Required:

MacLachlan, M. (2004). Embodiment: Clinical, critical and cultural perspectives on health and illness. New York: McGraw-Hill International.

Chapter 1, pp. 1-23

Chapter 2, pp. 25-45 
Chapter 3, pp. 48-81

Chapter 4, pp .84-106

Chapter 7, pp. 170-79

Recommended:

Weiss, G. (2013). Body images: Embodiment as intercorporeality. Routledge.

Introduction, pp. 1-6

Chapter 1, pp. 7-39

Chapter 3, pp. 65-86

Chapter 4, pp. 87-102

Chapter 7, pp. 129-63

Conclusion, pp. 166-70

Leder, D (1990). The Absent Body. Chicago: The University of Chicago Press.

Introduction, pp. 1-10

Part 1: Phenomenological Investigations, pp. 11-102

WEEK 7: February 19th, 2015, READING WEEK

WEEK 8: February 26th, 2015

Sexuality Studies

Required:

Jackson, S., \& Scott, S. (2010). Theorizing sexuality. McGraw-Hill International.

Seidman, S. (2003). The social construction of sexuality. New York: Norton.

Recommended:

Stoler, A. (1995). Race and the education of desire: Foucault's history of sexuality and the colonial order of things. Duke University Press.

WEEK 9: March 5th, 2015

Sexuality Studies II

Required:

Gavey, N. (2012). Beyond "empowerment"? Sexuality in a sexist world. Sexroles, 66(1112), 718-24.

Hammonds, E. (2004). Black (w) holes and the geometry of black female sexuality. The Black studies reader, 301-14.

Recommended:

Egan, R. D. (2013). Becoming sexual: A critical appraisal of the sexualization of girls. John Wiley \& Sons. 
WEEK 10: March 12, 2015

The Becoming of Bodies: Toward a Corporeal Feminism

Required:

Grosz, E. A. (1994). Volatile bodies: Toward a corporeal feminism. Indiana University Press.

Chapter 1: Refiguring Bodies, pp. 3-27

Chapter 4: Lived Bodies, pp. 86-114

Chapter 5: Nietzsche and the Choreography of Knowledge, pp. 115-37

Chapter 6: The Body as Inscriptive Surface, pp. 138-59

Chapter 7: Intensities and Flows, pp. 160-86

Chapter 8: Sexed Bodies, pp. 187-210

Recommended:

Grosz, E. (2004). The nick of time: Politics, evolution, and the untimely. Duke University Press.

Introduction

Grosz, E. (2011). Becoming undone. Durham \& London: Duke University Press.

Section III: The New Materialisms

WEEK 11: March 19th, 2015

Introducing the New Materialisms

Required:

Alaimo, S., \& Hekman, S. (Eds.). (2007). Material Feminisms. Indiana University Press.

Introduction: Emerging models of materiality in feminist theory, pp. 1-22

Chapter 1: Darwin and feminism: Preliminary investigations for a possible alliance, pp. 23-51

Chapter 3: Constructing the ballast: An ontology for feminism, pp. 85-119

Recommended:

Coole, D., \& Frost, S. (Eds.). (2010). New Materialisms: Ontology, Agency, and Politics. Durham \& London: Duke University Press.

Introducing the new materialisms, pp. 1-43 The Inertia of Matter and the Generativity of Flesh, pp. 92-115

Fear and the Illusion of Autonomy, pp. 158-77 
Materialities of Experience, pp. 178-200 Birke, L. (2000). Feminism and the biological body. New Brunswick, NJ: Rutgers University Press.

WEEK 12: March 26th, 2015

Sex, Gender and the New Materialisms

Required:

Fausto-Sterling, A. (2012). Sex/gender: Biology in a social world. London and New York: Routledge.

Hird, Myra J. (2004) Sex, Gender, and Science. New York: Palgrave Macmillan.

Chapter 1: Introduction, pp. 1-16

Chapter 2: Making Sex, Making Sexual Difference, pp. 17-28

Chapter 3: The Body of Sexual Difference, pp. 29-49

Chapter 4: New Materialism, Nonlinear Biology, and the Superabundance of Diversity pp. $50-71$

Chapter 5: The Nonlinear Evolution of Human Sex, pp. 72-89

Chapter 6: Sex Diversity in Nonhuman Animals, pp. 90-121

Chapter 7: Sex Diversity in Human Animals, pp. 122-42

Chapter 8: How to Have Sex Without Women or Men, pp. 143-52

Recommended:

Barad, K. (2003). Posthumanist Performativity: Toward an Understanding of How Matter Comes to Matter. Signs: Journal of Women in Culture and Society, 28(3), 801-31.

Barad, K. (2011). Nature's queer performativity. Qui Parle: Critical Humanities and Social Sciences, 19(2), 121-58.

Section IV: Toward Feminist Posthumanism

WEEK 13: April 2nd, 2015

What is the Posthuman?

Required:

Braidotti, R. (2013). The Posthuman. Cambridge: Polity Press.

Introduction, pp. 1-12

Chapter 1: Post-Humanism: Life Beyond the Self, pp. 13-54

Chapter 4: Posthuman Humanities: Life Beyond Theory, pp. 143-85

Conclusion, pp. 186-97 
Recommended:

Braidotti, R. (2011). Nomadic theory: The portable Rosi Braidotti. Columbia University Press.

Introduction, pp. 1-24

Chapter 5: Matter-realist Feminism, pp. 127-49 Wolfe, C. (2010). What is posthumanism? University of Minnesota Press. Introduction, pp. xi-xxxiv

Chapter 1: Meaning and Event, pp. 3-30 Chapter 2: Language, Representation, and Species, pp. 31-48

Chapter 3: Flesh and Finitude, pp. 49-98

Chapter 4: Animal Studies, Disciplinarity, and the (post) Humanities, pp. 99-126

Chapter 5: Learning from Temple Grandin, pp. 127-43

Recommended:

Haraway, D. (1991). A Cyborg Manifesto: Science, Technology, and Socialist-Feminism in the Late Twentieth Century. In Simians, Cyborgs and Women: The Reinvention of Nature (pp. 149-181). New York: Routledge.

Coleman, R., \& Ringrose, J. (Eds.). (2013). Deleuze and research methodologies. Edinburgh University Press.

\section{Works cited}

Braidotti, Rosi. The Posthuman. Polity Press, 2013.

Bright, Clare. "Teaching Feminist Pedagogy: An Undergraduate Course." Women's Studies Quarterly, vol. 21, nos. 3/4, 1993, pp. 128-32.

Brown, Caroline, and Alexia Pollack. "Reconstructing the Paradigm: Teaching Across the Disciplines." The Journal of Undergraduate Neuroscience Education, vol. 3, no. 1, 2004, pp. A9-A15.

Bryson, B. J., and Victoria Bennet-Anylkwa. "The Teaching and Learning Experience: Deconstructing and Creating Space Using Feminist Pedagogy." Race, Gender \& Class, vol. 10, no. 2, 2003, pp. 131-46.

Charmaz, Kathy. "Grounded Theory." Rethinking Methods in Psychology, edited by Jonathan A. Smith et al., Sage Publications, 1995, pp. 27-49. 
—. "Grounded Theory: Methodology and Theory Construction." International

Encyclopedia of the Social \& Behavioural Sciences. Elsevier Science, 2001, pp. 6396-99.

De Santis, Carm, and Toni Serafini. "Classroom to Community: Reflections on Experiential Learning and Socially Just Citizenship." Feminist Pedagogy in Higher Learning, edited by Tracy Penny Light et al., Wilfred Laurier Press, 2016, pp. 87112.

do Mar Pereira, Maria. "Uncomfortable Classrooms: Rethinking the Role of Student Discomfort in Feminist Teaching." European Journal of Women's Studies, vol 19, no. 1, 2012, pp. 128-35.

Donadey, Anne. "Negotiating Tensions: Teaching About Race Issues in Graduate Feminist Classrooms." NWSA Journal, vol. 14, no. 1, 2002, pp. 82-102.

Fisher, Berenice. "The Heart Has Its Reasons: Feeling, Thinking and Community Building in Feminist Education." Women's Studies Quarterly, vol. 21, nos. 3/4, 1993, pp. 75-87.

Fisher, Jerilyn. "Returning Women in the Feminist Classroom." Women's Studies Quarterly, vol. 21, nos. 2/3, 1993, pp. 122-27.

Gardiner, Judith K. "Paradoxes of Empowerment: Interdisciplinary Graduate Pedagogy in Women's Studies." Feminist Studies, vol. 29, no. 2, 2003, pp. 409-21.

Hemmings, Clare. "Collective Powers: Rupture and Displacement in Feminist Pedagogic Practice." European Journal of Women's Studies, vol. 18, no. 3, 2011, pp. 296303.

Hobbs, Margaret, and Carla Rice. "Introduction: Mapping the Terrain of Gender and Women's Studies in Canada." Gender and Women's Studies in Canada: Critical Terrain, edited by Margaret Hobbs and Carla Rice, Women's Press, 2013, pp. xvii-xxviii.

—. "Rethinking Women's Studies: Curriculum, Pedagogy, and the Introductory Course." Atlantis: Critical Studies in Gender, Culture \& Social Justice, vol. 35, no. 2, 2012, pp. 139-49. 
Kenway, Jane, and Helen Modra. "Feminist Pedagogy and Emancipatory Possibilities." Feminisms and Critical Pedagogy, edited by Carmen Luke and Jennifer Gore, Routledge, 1992, pp. 138-66.

Kishimoto, Kyoko, and Mumbi Mwangi. "Critiquing the Rhetoric of 'Safety' in Feminist Pedagogy: Women of Color Offering an Account of Ourselves." Feminist Teacher, vol. 19, no. 2, 2009, pp. 87-102.

Maher, Frances A., and Mary Kay Thompson Tetreault. The Feminist Classroom. Basic Books, 1994.

Martin, Jane Roland. "Becoming Educated: A Journey of Alienation or Integration." Journal of Education, vol. 167, no. 3, 1985, pp. 71-84.

Mayberry, Maralee, and Margaret N. Rees. "Feminist Pedagogy, Interdisciplinary Praxis, and Science Education." NWSA Journal, vol. 9, no. 1, 1997, pp. 57-75.

Maynes, Mary Jo. "In the Classroom: Gender, Genre, and Political Transformation-An Interdisciplinary Graduate Research Seminar." Journal of Women's History, vol. 15, no. 3, 2003, pp. 118-23.

Nixon, Debra Harris, et al. "Creating Community: Offering a Liberation Pedagogical Model to Facilitate Diversity Conversations in MFT Graduate Classrooms." Journal of Marital and Family Therapy, vol. 36, no. 2, 2010, pp. 197-211.

Seymour, Nicole. "The Interests of Full Disclosure: Agenda-Setting and the Practical Initiation of the Feminist Classroom." Feminist Teacher, vol. 17, no. 3, 2007, pp. 187-203.

Shildrick, Margrit. "Fabrica(tions): On the Construction of the Human Body." Leaky Bodies and Boundaries: Feminism, Postmodernism and (Bio)ethics, edited by Margrit Shildrick. Routledge, 1997, pp.13-61.

Shrewsbury, Carolyn M. "What is Feminist Pedagogy?” Women's Studies Quarterly, vol. 21, nos. 3/4, 1993, pp. 8-16.

Spencer, Leland. "Engaging Undergraduates in Feminist Classrooms: An Exploration of Professors'Practices." Equity \& Excellent in Education, vol. 48, no. 2, 2015, pp. 195211.

USGS Water Science School. "The Water in You." United States Geological Survey, 9 Dec. 2015, water.usgs.gov/edu/propertyyou.html. Accessed 27 Dec. 2015. 
Weiss, Gail. Body Images: Embodiment as Intercorporeality. Routledge, 1999. 